\title{
A Muscle-Derived Factor(s) Induces Expression of a Catecholamine Phenotype in Neurons of Cultured Rat Cerebral Cortex
}

\author{
Lorraine lacovitti, Marian J. Evinger, Tong H. Joh, ${ }^{a}$ and Donald J. Reis \\ Division of Neurobiology, Cornell University Medical College, New York, New York 10021
}

We sought to determine the source of the signal(s) that promotes expression of the catecholamine (CA) enzyme tyrosine hydroxylase (TH) in cultured neurons of embryonic rat cerebral cortex, a tissue which is not thought to contain CA cells in vivo. Cortical neurons were cultured with their nonneuronal constituents and $\mathbf{4 8} \mathbf{~ h r}$ later immunostained for TH. Fibroblasts or glia had no effects, however, blood vessels increased the numbers of TH neurons nearly 4-fold. Coculture with either perinatal aorta, skeletal or cardiac muscle, clonal muscle cell lines 1440 (smooth) and L6 (skeletal), conditioned media from L6 cells, or a soluble extract of L6 cells increased the number of TH neurons up to 20 -fold. The induction of TH by muscle extract was (1) dose dependent; (2) paralleled by a proportional increase in the steady-state levels of TH mRNA; (3) greatly reduced by the RNA synthesis inhibitor $\alpha$-amanitin or the protein synthesis inhibitor cycloheximide; and (4) unassociated with change in the survival of neurons in culture. The response was not replicated by treatment with other established neurotrophic substances, Including NGF, EGF, FGF, PDGF, neuroleukin, insulin, pyruvate, $\mathrm{KCl}$, adenosine, or inosine. We conclude that muscle contains a potentially novel substance, muscle-derived differentiation factor (MDF) that promotes differentiation but not survival of neurons of cerebral cortex by de novo synthesis of TH mRNA and TH protein. Thus, neurons of the CNS, as in periphery, may undergo phenotypic interconversion in response to biologically derived molecules in their environment.

When neurons of the cerebral cortex of the embryonic rat are placed in tissue culture (Iacovitti et al., 1987) or are transplanted into the cerebral cortex of adult mouse (Park et al., 1986; Herman et al., 1988), a substantial number of these neurons express the catecholamine (CA) biosynthetic enzyme tyrosine hydroxylase $(\mathrm{TH})$. Since in vivo $\mathrm{CA}$ neurons are rarely, if ever, detected in the cerebral cortex of embryonic or adult rat (Ungerstedt, 1971; Specht et al., 1981; Kohler et al., 1983; Berger et al., 1985), the observation suggests that neurotransmitter enzyme

\footnotetext{
Received Mar. 14, 1989; accepted Apr. 11, 1989.

This work was supported by grants from the National Institutes of Health (1R01 NS24204 to L.I.; PPC 5-PO1-HL18974 to D.J.R. and L.I.). Special thanks to G. Teitelman for many helpful discussions, and L. Lyandvert and M. Moustakos for excellent technical assistance.

Correspondence should be addressed to Lorraine Iacovitti at her present address: Department of Neurology, Hahnemann University, Broad and Vine Streets, Philadelphia, PA 19102.

aresent address: Laboratory of Molecular Neurobiology, Burke Rehabilitation Center, 725 Mamaroneck Avenue, White Plains, NY 10605.

Copyright (C) 1989 Society for Neuroscience $0270-6474 / 89 / 103529-09 \$ 02.00 / 0$
}

plasticity, previously believed to be a property displayed by neurons of the peripheral nervous system (Bunge et al., 1978; Patterson, 1978; Iacovitti et al., 1985; Teitelman et al., 1985), may also be shared by intrinsic neurons of the CNS. The mechanism governing the phenotypic interconversion of neurons of the rat cortex when placed in culture or into host brain is unknown. One possibility is that some molecule, common to the microenvironment of the culture and the graft site might initiate the event.

In the present study we therefore sought to determine whether non-neuronal constituents of brain, specifically fibroblasts, glia, or blood vessels, could evoke the expression of $\mathrm{TH}$ in cultured cortical ncurons of rat cmbryo. We report that a soluble and potentially novel substance originating in vascular and other types of muscle, muscle-derived differentiation factor (MDF), will dramatically increase from 0.5 to $10 \%$ the number of cortical neurons expressing TH. MDF induces TH by de novo synthesis of TH mRNA and $\mathrm{TH}$ protein in preexisting cortical neurons without affecting their survival in culture. The findings indicate that the expression of neurotransmitter enzymes may be epigenetically modified in central as in peripheral neurons by molecules in the microenvironment.

\section{Materials and Methods}

Tissue culture. Cerebral cortices were dissected from 13-d-old rat (Sprague-Dawley) embryos, trypsin-dissociated $(0.01 \%)$, and plated on collagen-coated tissue culture dishes at a density of $1 \times 10^{5} \mathrm{cells} / \mathrm{dish}$ as previously described (Iacovitti et al., 1981). Cultures were grown either on control medium containing fetal calf serum $(10 \%)$ or in a serumless defined medium (Bottenstein and Sato, 1979), both of which yielded similar results. In all coculture experiments, cortical cells were plated onto confluent layers of non-neuronal cells isolated from 1-d-old rat pups. Glia were generated from cerebral cortices as described by McCarthy and de Vellis (1980), fibroblast layers were derived from either skin or lung and muscle from either aorta (smooth), heart (cardiac), gluteal (skeletal) muscle, or from the clonal smooth muscle cell line 1440 or the skeletal muscle cell line, L6 (available from ATCC).

Preparation of soluble L6 fraction (MDF). To prepare soluble extracts of muscle, cultures of confluent L6 muscle cells were grown for $10 \mathrm{~d}$ in

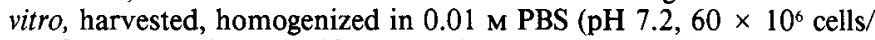
$\mathrm{ml}$ ) for $30 \mathrm{sec}$ with a Sonifier Cell Disrupter and centrifuged at 40,000 $\times g$ for $1 \mathrm{hr}$ to separate soluble and insoluble fractions. The clear supernatants were collected and protein levels determined.

Immunocytochemistry. Cultures were fixed in $4 \%$ paraformaldehyde in $0.1 \mathrm{M}$ phosphate buffer $(\mathrm{pH} 7.4)$ and processed with antibodies to TH (1:1000 dilution, gift of Dr. T. H. Joh) or neuron-specific enolase (NSE) (1:500 dilution, Polysciences, Inc.) according to the PAP method (Sternberger, 1974) as previously modified for tissue culture (Iacovitti et al., 1981). Except where stated otherwise, TH cell numbers were determined by counting stained cells in all microscopic fields on the culture dish. This was accomplished with the aid of an eyepiece reticule used at a $10 \times$ magnification.

Enzyme assay. Prior to biochemical analysis, all cultures were rinsed in PBS (pH 7.2) and excess rinse was carefully blotted. Cultures, in- 
Table 1. Number of TH-immunoreactive cortical neurons after coculture of cortex with various tissues

\begin{tabular}{lc} 
Tissue in culture & $\begin{array}{c}\text { Number of TH } \\
\text { neurons/culture }\end{array}$ \\
\hline Cerebral cortex & $1417 \pm 178$ \\
+ Glia & $1388 \pm 111$ \\
+ Fibroblasts (skin, lung) & $1509 \pm 201$ \\
+ Aorta & $5468 \pm 322$ \\
+ Cardiac muscle & $6719 \pm 644$ \\
+ Skeletal muscle & $9774 \pm 1096$ \\
+ 1440 smooth muscle & $7989 \pm 414$ \\
+ L6 skeletal muscle & $11,886 \pm 1890$
\end{tabular}

Cortical cells were grown alone or in coculture with non-neuronal cell layers. After $2 \mathrm{~d}$, cultures were fixed, processed for the immunocytochemical localization of $\mathrm{TH}$, and the number of TH-immunoreactive cortical neurons counted in all microscopic fields. All values represent the mean \pm SEM for duplicate cultures in 3 separate platings.

cluding collagen substratum, were dissected free of the culture dish, frozen on dry ice, and stored at $-80^{\circ} \mathrm{C}$. For enzyme assay, tissues were homogenized in 5 mm potassium phosphate buffer ( $\mathrm{pH} 7.0$ ) containing $0.2 \%$ Triton X-100 (vol $/ \mathrm{vol})$ at a dilution that insured that the reaction was linear with enzyme concentration and time. The homogenate was centrifuged at $10,000 \times g$ for $10 \mathrm{~min}, 4^{\circ} \mathrm{C}$, and the supernatant decanted for assay of TH enzyme activity by the method of Coyle (1972).

$D N A$ determination. Cultures fed either control or supplemented media were rinsed, harvested, and pooled into groups of 3 cultures each. Cell pellets from each sample were digested in proteinase $\mathrm{K}(100 \mu \mathrm{g})$ $\mathrm{ml}$ )-SDS, $50-55^{\circ} \mathrm{C}$ overnight. DNA was phenol-extracted, then incubated in RNAse $\left(2.5 \mathrm{mg} / \mathrm{ml}, 37^{\circ} \mathrm{C}, 30 \mathrm{~min}\right)$. The amount of DNA in each sample was determined spectrophotometrically.

Quantitative hybridization. Total cellular RNA was isolated from cortical cultures grown in control or muscle fraction-supplemented media using previously described methods (Ausubel et al., 1987). RNAs were fractionated by electrophoresis on a $1.1 \%$ agarose-formaldehyde gel and transferred to nitrocellulose. RNA was then hybridized with a ${ }^{32} \mathrm{P}-\mathrm{la}-$ beled TH cRNA probe (kind gift of Dr. T. H. Joh) (380 ntd) (specific activity $=3-10 \times 10^{8} \mathrm{cpm} / \mathrm{gm}$ ). Autoradiograms were developed after a 3-5 d exposure at $-80^{\circ} \mathrm{C}$. Under these conditions, TH cRNA is capable of detccting TH mRNA in $0.33 \mathrm{gm}$ adult rat substantia nigra total RNA (T. Shirao, unpublished observations). Total RNA from cortical cultures was then translated in vitro and immunoprecipitated with $\mathrm{TH}$ antibodies before fractionation on a $10 \%$ SDS-polyacrylamide gel and fluorography.

For quantitative analyses, RNAs were denatured as previously described and then adjusted to $10 \times$ SSC for binding to Nylon filters using a Manifold II Slot Blot apparatus. Filters were hybridized, treated with DNase-free RNase A $(1.0 \mu \mathrm{g} / \mathrm{ml})$ in $2 \times \mathrm{SSC}$ for $30 \mathrm{~min}$ at $37^{\circ} \mathrm{C}$, washed, and exposed for autoradiography as described for gel transfers.

Comparisons of the relative amounts of TH mRNA was achieved by densitometric scanning (LKB Ultralaser densitometer) of autoradiographic intensities. Serial dilutions of polysomal RNA from bovine adrenal medulla serves as a standard curve for estimation of mRNA levels.

Table 2. TH expression in cerebral cortex cocultured with L6 muscle

\begin{tabular}{lcl} 
& $\begin{array}{c}\text { Number of TH } \\
\text { neurons/culture }\end{array}$ & $\begin{array}{l}\text { pmol dopa/ } \\
\text { hr/culture }\end{array}$ \\
\hline Cerebral cortex & $2021 \pm 401$ & $0.52 \pm 0.14$ \\
L6 muscle & 0 & 0 \\
Cerebral cortex + L6 muscle & $18,587 \pm 1499$ & $5.96 \pm 0.98$
\end{tabular}

Cultures containing either cortical cells or L6 muscle cells only, or cortical plus muscle cells were fixed and processed for immunocytochemistry or were pooled and assayed for TH enzyme activity. Values represent means \pm SEM of triplicate cultures in 2 separate platings.
Table 3. Number of TH-containing cortical neurons grown with various components of $\mathrm{L} 6$ muscle

\begin{tabular}{lc} 
Conditions in culture & $\begin{array}{c}\text { Number of TH } \\
\text { neurons/culture }\end{array}$ \\
\hline Cerebral cortex & $1632 \pm 409$ \\
Cerebral cortex + CM from L6 & $6676 \pm 988$ \\
Cerebral cortex + membrane fraction of L6 & \\
$\quad\left(\mathbf{P}^{2}\right.$ pellet $)$ & $1512 \pm 202$ \\
Cerebral cortex + soluble fraction of L6 & $22,704 \pm 1791$
\end{tabular}

E13 cortical cells were grown either on control medium or on $(100 \%)$ medium previously conditioned for $3 \mathrm{~d}$ by confluent layers of L6 muscle cells, or on the soluble or insoluble fraction of L6 muscle (prepared as described in Materials and Methods). After $2 \mathrm{~d}$ in vitro, cultures were fixed and stained and the number of TH neurons counted. All values represent means \pm SEM for duplicate cultures from 4 separate platings.

\section{Results}

Effects of coculture of cortex with non-neural constitutents of brain

When cerebral cortices were isolated from rat embryos at midgestation (E13), dissociated into single cells, and maintained in culture for $2 \mathrm{~d}$, about 1400 neurons, representing $0.5 \%$ of the approximately 300,000 surviving neurons in each culture dish, stained with antibodies to TH (Table 1), confirming our earlier observations (Iacovitti et al., 1987). Omission of serum from the media did not eliminate the appearance of TH in cortical neurons (unpublished observations), suggesting that it was the cellular elements of the culture environment that may have promoted the unexpected expression of this enzyme. In addition to neurons, cortical cultures contained sparse numbers of glioblasts and fibroblasts at plating. Since these non-neuronal cells rapidly multiply while in culture, we assessed their potential role in mediating this effect by coculturing cortical neurons with confluent layers of perinatal glia or fibroblasts. As evidenced in Table 1, increasing the number of non-neuronal cells in culture had no effect on the expression of TH in cortex. Since these experiments utilized non-neuronal cells isolated from older animals, it is important to note that in cultures containing only E13 cortical cells, we never observed a positive correlation between the number of TH neurons and the number of non-neuronal cells present.

Several observations led us to next test the potential role of blood vessels in the regulation of TH expression in cortex. First, transplants of embryonic cortex contained abundant TH neurons at the graft/host border, the site of greatest vascularization, with some neurons in intimate contact with blood vessels (Park et al., 1986). Second, during our own dissection procedure, most cerebral vessels remained with the cortical tissue at the time of their dissociation for culture. To test the potential interaction of these 2 tissues, aortas from E2l embryos were dissociated and plated into culture. Five days later, cortical cells were added to the dishcs. Cocultures were fixed and analyzed $2 \mathrm{~d}$ later. We found that, in the presence of aorta, the number of TH neurons was increased almost 4 -fold (Table 1 ).

Blood vessels contain fibroblasts, smooth muscle, and endothelium. Since fibroblasts did not themselves increase TH expression, we examined the effect of the addition of various types of muscle cells on embryonic cerebral cortex. Coculture of cortex with a clonal smooth muscle (1440) or skeletal muscle (L6) cell line, or with embryonic cardiac or skeletal muscle 
markedly increased the number of neurons expressing $\mathrm{TH}$ in the cerebral cortex. L6 cells were the most potent inducers, increasing the numbers of TH-immunoreactive cells by 8 -fold (Table 1).

\section{Effects of muscle on $\mathrm{TH}$ activity}

The increase in TH immunoreactivity in cortical neurons elicited by coculture with muscle was associated with a 10 -fold and, hence, proportional, increase in TH enzymatic activity (Table 2 ), indicating that the induced enzyme was catalytically active. The level of TH activity in induced cortical cultures approximated $10 \%$ of that measured in short-term cultures of central CA neurons of the substantia nigra $(40 \mathrm{fmol} / \mathrm{TH}$ neuron $/ \mathrm{hr}$ in $7 \mathrm{~d}$ cultures) (unpublished observations).

\section{Effects of soluble and insoluble muscle components on CA differentiation}

In a preliminary experiment we observed that media obtained from cultures of confluent L6 cells, when added to cultured cerebral cortices, increased the number of TH-positive neurons in a culture plate 4 -fold (Table 3 ). This observation suggested that a soluble and diffusible substance(s) produced in muscle was capable of inducing $\mathrm{TH}$ in cortical neurons. To test the premise, L6 cells were homogenized, fractionated into soluble (cytosolic) and insoluble (membrane) components by high-speed centrifugation (see Materials and Methods), and added separately to cultures of cortical neurons.

The insoluble fraction of muscle (resuspended in media to a final concentration of $1.0-12.0 \mathrm{mg}$ protein $/ \mathrm{ml}$ ) did not increase TH expression in cortex (Table 3). In contrast, the soluble fraction clicited a dosc-dependent increase in the number of THimmunoreactive cortical neurons, which, at the highest concentration tested, was 20 -fold greater than control (Figs. 1, 2). Thus, the effects of coculture of muscle on the expression of TH immunoreactivity can be attributed to release of a soluble material from muscle and not to cellular contact between muscle and neuron.

\section{Action of muscle factor on neuronal survival and differentiation}

The induction of $\mathrm{TH}$ in cortical neurons by muscle might be explained in one of several ways. Muscle might contain a neurotrophic factor(s) that increases the viability of all cortical neurons or specifically the class of neurons competent to express $\mathrm{TH}$, or it might act as a specifying factor(s) that induces the differentiation of neurons without affecting their survival. In the former case, an increase in total cell number would be expected. As an index of cell number, we measured the DNA content in control cultures and in those supplemented with soluble muscle fraction. The total number of cortical cells surviving in culture

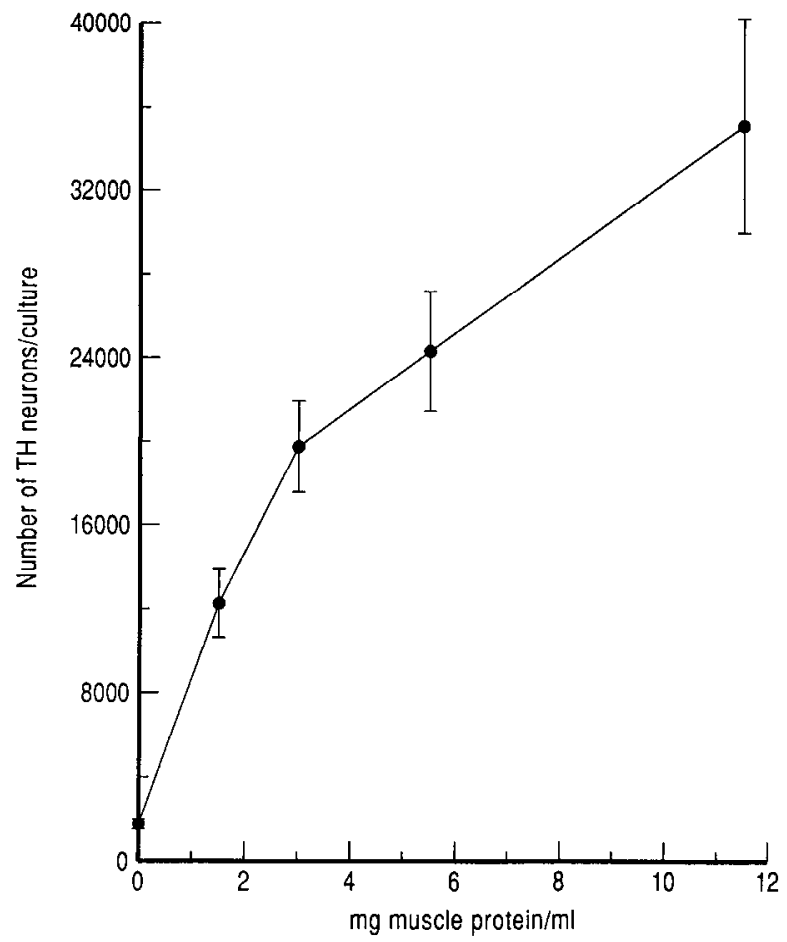

Figure 1. Dose-response curve for TH expression in cortical neurons grown on soluble muscle factors. Cortical cells (E13) were dissociated and plated in medium containing serial dilutions of the soluble muscle fraction or into control medium containing comparable levels of BSA protein. Concentrations greater than $12 \mathrm{mg}$ protein $/ \mathrm{ml}$ resulted in the formation of precipitate in the media and were therefore not tested in these experiments. After $2 \mathrm{~d}$ incubation, cultures were fixed, stained and the number of TH immunoreactive cells counted. Values represent mean \pm SEM of triplicate cultures from 2 separate platings.

was increased when soluble muscle factors were added to the culture, as indicated by a 1.5 -fold greater concentration in DNA in muscle-supplemented cultures as compared with controls (Table 4). However, microscopic analysis of individual cultures indicated that this increase occurred predominantly in the fibroblast component of the culture and not in the neuronal cell population. Thus, there was no increment in the number of cells that stained positively for the neuronal marker, NSE (Table 4). Consequently, muscle contains factors that can affect the survival of certain cell types, such as fibroblasts, but does not increase the total number of surviving neurons.

Since only a fraction (10\%) of the total neurons in culture are capable of TH expression, it is possible that changes in the survival of this select group might be masked in total cell counts. We therefore addressed this issue in yet another way. Cortical

Table 4. Effects of muscle factor(s) on cortical cell number

\begin{tabular}{lllc} 
Tissue & DNA $(\mu \mathrm{g})$ & $\begin{array}{l}\text { Number NSE } \\
\text { neurons/culture }\end{array}$ & $\begin{array}{c}\text { Number } \text { TH }^{+} \\
\text {neurons/culture }\end{array}$ \\
\hline Cerebral cortex & $3.4 \pm 0.3$ & $307,396 \pm 3438$ & $1471 \pm 116$ \\
Cerebral cortex + soluble L6 fraction & $5.0 \pm 0.2$ & $304,728 \pm 2899$ & $21,481 \pm 2002$
\end{tabular}

E13 cortical cells were grown on control medium or on $80 \%$ soluble muscle fraction (prepared as described in Materials and Methods). After $2 \mathrm{~d}$ in vitro, cultures were harvested, pooled DNA was extracted, and the amount of DNA determined spectrophotometrically. Sister cultures were simultaneously fixed and stained with either antibodies to TH or NSE, and the number of stained neurons counted. Values represent the means of duplicate cultures from 2 separate platings. 

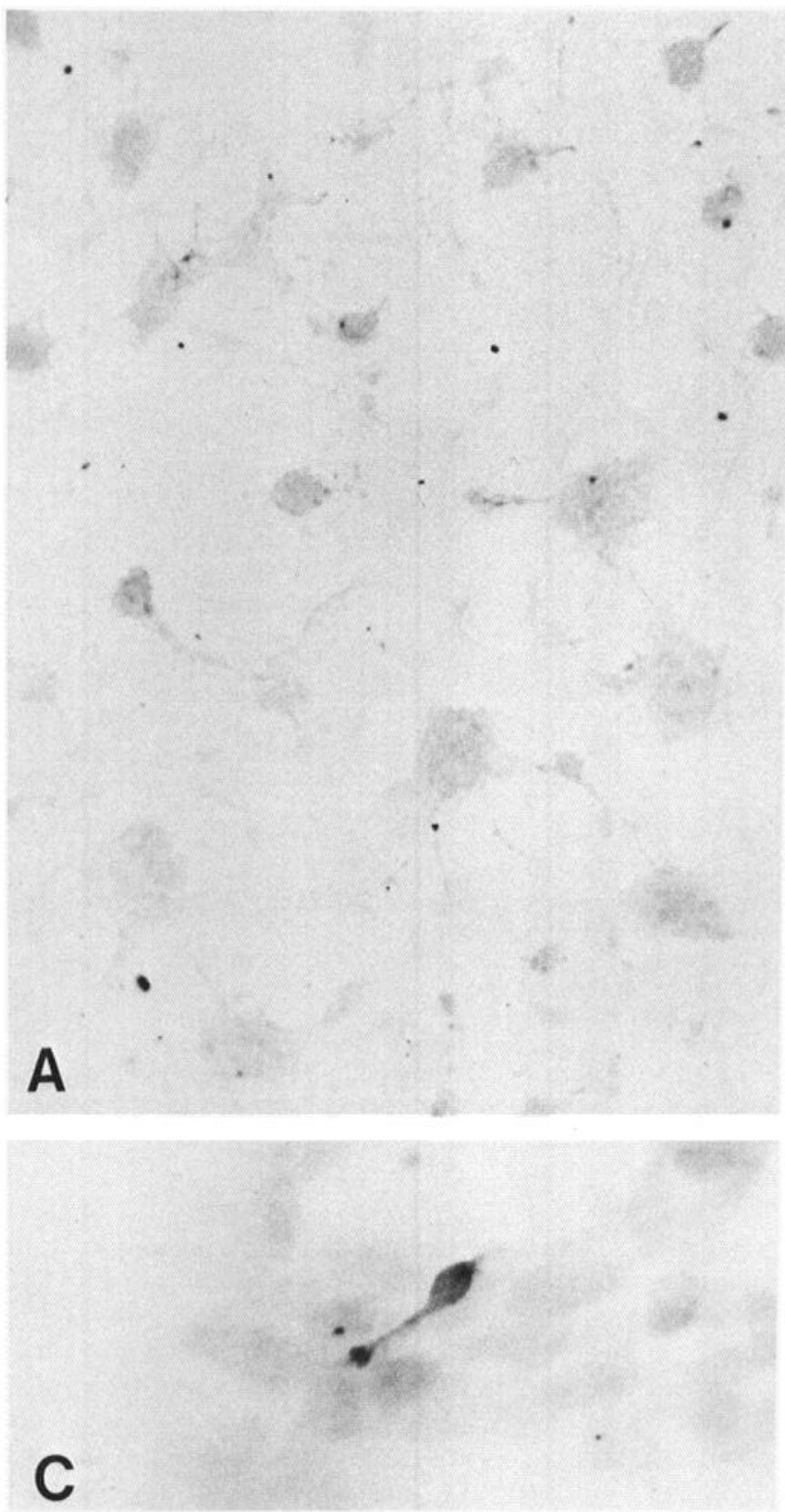

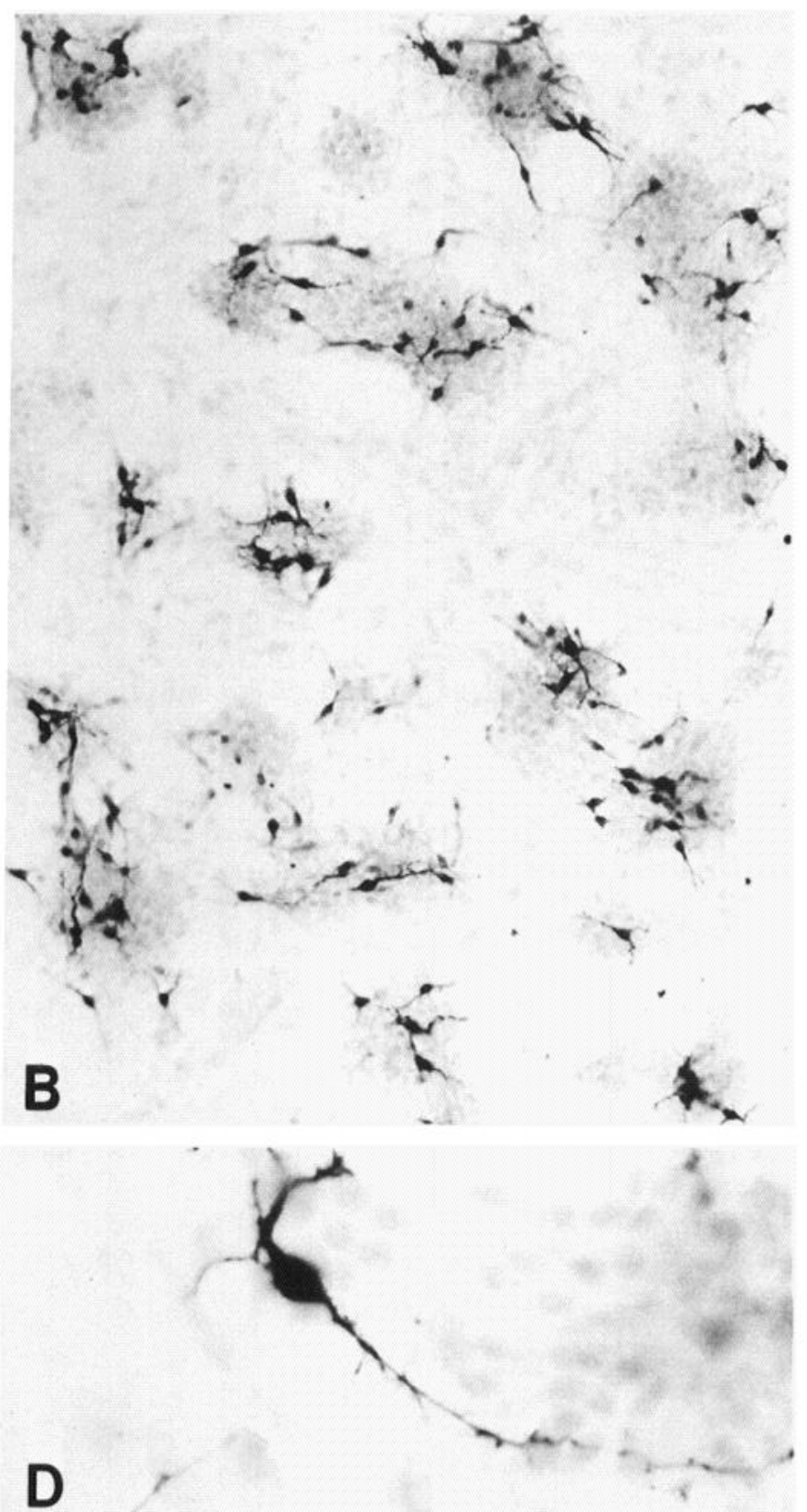

Figure 2. Effect of soluble muscle factor(s) on TH expression in cultures of cerebral cortex. Low-power $(A, B)$ and high-power $(C, D)$ photomicrographs are shown of cortical cells grown either on control media $(A, C)$ or in the presence of soluble muscle fraction $(B, D)$.

cells were seeded, as usual, on control or muscle fraction-supplemented media. Twenty-four hours later, after neuronal viability had stabilized, several control cultures were rinsed of loosely adherent cells and subsequently tested for TH induction by the addition of muscle factor or comparable amounts of BSA protein to the media. One day later, cultures in all groups were stained with antibodies to $\mathrm{TH}$ and counted. Treatment with muscle factors increased, by 18 - to 20 -fold, the proportion of TH-immunoreactive neurons (Table 5) regardless of the time of supplementation. Since at $24 \mathrm{hr}$ there is no new pool of cells from which to recruit neurons, a selective improvement in neuronal survival rate cannot account for the increase in $\mathrm{TH}$ cell number.

Furthermore, the overall health of neurons did not appear to be significantly improved by supplementation with muscle factor(s) since the growth and morphology of neurons stained with the marker enzyme NSE remained the same in treated and untreated cultures. Interestingly, however, when stained for TH, neurons grown in muscle fraction were morphologically distinct from those grown in control media: stained perikarya were sometimes larger with more darkly stained cytoplasm and with more numerous neuritic processes (compare Fig. 2, $C, D$ ). Enhanced visualization of the morphology of neurons containing induced levels of the enzyme, as the case may be after treatment with muscle fraction, may well account for these differences.

Since there is no apparent improvement in the health or survival of neurons in culture, it seems most likely that muscle contains a soluble molecule(s) that promotes the differentiation 
of CA traits in a greater number of existing cortical neurons. We call this putative agent(s) MDF.

\section{Effects of muscle factor on TH $m R N A$ and TH protein in cortical neurons}

We examined whether the increment in TH cell number and enzyme activity initiated by MDF was associated with an increase in TH mRNA. Cultures of cortical neurons incubated for $2 \mathrm{~d}$ in the presence or absence of MDF were harvested, and TH mRNA was extracted and quantitated by Northern analysis using a ${ }^{32}$ P-labeled TH cRNA probe (380 ntd).

MDF elicited in treated, but not in control, cultures the appearance of a single mRNA band (1900 ntd) corresponding to TH (Fig. 3, $A, B$ ). With translation in vitro, the mRNA produced an immunoprecipitable $60 \mathrm{kDa}$ protein, also corresponding to authentic enzyme (Fig. 3C). The alterations in the levels of TH mRNA by MDF were quantified by densitometry using slot blot analyses. In 2 separate experiments, equivalent amounts of total RNAs were analyzed in control and MDF treated cortical cultures (Fig. $3 D$ ). Following hybridization with TH cRNA and RNase A treatment, autoradiograms were analyzed by densitometric scanning. A standard curve depicting hybridization of the TH probe to serial dilutions of bovine adrenal medullary polysomal RNA allows estimation of relative amounts of TH mRNA in the cortical cultures. In experiment 1 , MDF supplementation increased TH mRNA 3.6-fold over control. In experiment 2, using a different preparation of MDF, TH mRNA was increased 9.6-fold as compared with control.
Table 5. TH expression in cerebral cortex cocultured with L6 muscle

\begin{tabular}{llc} 
Medium & $\begin{array}{l}\text { Time of MDF } \\
\text { supplementation }\end{array}$ & $\begin{array}{l}\text { Proportion of } \\
\mathrm{TH}^{+} \text {neurons/ } \\
\text { culture (\%) }\end{array}$ \\
\hline- MDF & - & $0.5 \pm 0.3$ \\
+ MDF & $0 \mathrm{hr}$ (plating) & $9 \pm 4$ \\
+ MDF & $24 \mathrm{hr}$ aftcr plating & $10 \pm 2$
\end{tabular}

Embryonic rat cortical cells were grown either on control medium or on medium supplemented with MDF at various times after plating. Cultures were fixed after $48 \mathrm{hr}$ total time in culture, and the number of TH neurons was determined. In each culture, the total number of phase-bright neurons were counted in 20 selected microscopic fields $(10 \times, 25 \times)$. The proportion of neurons which were THimmunoreactive was simultaneously determined using bright-field optics. Values represent means \pm SEM of duplicate cultures from 2 separate platings.

These results indicate that MDF elevates the steady-state level of TH mRNA and that the increase in TH mRNA elicited by MDF was comparable in magnitude to both the increases in numbers of immunoreactive neurons in the culture and the catalytic activity of the enzyme.

\section{Effects of inhibition of transcription and translation on the action of $M D F$}

To determine whether the increase of TH mRNA elicited by MDF was associated with de novo synthesis of message and/or specific protein, varying concentrations of $\alpha$-amanitin, an inhibitor of RNA polymerases (Roeder, 1976), or cycloheximide, an inhibitor of protein biosynthesis, was added to cultures of

Table 6. Substances which do not mimic or inhibit the action of MDF

\begin{tabular}{|c|c|c|}
\hline Substance & Concentrations tested & $\begin{array}{l}\text { No. of TH } \\
\text { neurons/ } \\
\text { culture }\end{array}$ \\
\hline PBS & - & 2432 \\
\hline MDF & - & 20,205 \\
\hline Nerve growth factor ${ }^{a}$ & $10 \mathrm{ng} / \mathrm{ml}-1 \mu \mathrm{g} / \mathrm{ml}$ & 2219 \\
\hline MDF + antibodies to nerve growth factor ${ }^{a}$ & $1: 10-1: 100$ dilution ${ }^{\prime}$ & 22,583 \\
\hline Epidermal growth factor ${ }^{b}$ & $1 \mathrm{ng} / \mathrm{ml}-1 \mu \mathrm{g} / \mathrm{ml}$ & 2006 \\
\hline MDF + antibodies to epidermal growth factor ${ }^{c}$ & $1: 2-1: 4$ dilution $c$ & 22,114 \\
\hline Fibroblast growth factor (basic, acidic) ${ }^{b, d}$ & $1 \mathrm{ng} / \mathrm{ml}-100 \mathrm{ng} / \mathrm{ml}$ & 2329 \\
\hline MDF + antibodies to fibroblast growth factor (basic) ${ }^{d}$ & $0.1 \mathrm{ng} / \mathrm{ml}-100 \mathrm{ng} / \mathrm{ml}$ & 20,020 \\
\hline Platelet-derived growth factor ${ }^{d}$ & $1 \mathrm{ng} / \mathrm{ml}-100 \mathrm{ng} / \mathrm{ml}$ & 2088 \\
\hline Neuroleukin ${ }^{e}$ & $1 \mathrm{ng} / \mathrm{ml}-1 \mathrm{mg} / \mathrm{ml}$ & 2431 \\
\hline Insulin ${ }^{e}$ & $0.1 \mathrm{ng} / \mathrm{ml}-100 \mathrm{ng} / \mathrm{ml}$ & 2692 \\
\hline Dexamethasone & $0.1 \mu \mathrm{M}-10 \mu \mathrm{M}$ & 2387 \\
\hline Adenosine & $0.1 \mu \mathrm{M}-10 \mu \mathrm{M}$ & 2099 \\
\hline Inosine & $0.1 \mu \mathrm{M}-10 \mu \mathrm{M}$ & 2119 \\
\hline Pyruvate & $1.0 \mu \mathrm{M}-10 \mu \mathrm{M}$ & 2017 \\
\hline $\mathrm{KCl}$ & $4.0 \mu \mathrm{M}-40 \mu \mathrm{M}$ & 2499 \\
\hline
\end{tabular}

Cultures of $E 13$ cortical cells were grown for $2 \mathrm{~d}$ in the presence of each of the listed substances at a range of concentrations. In an attempt to inhibit the action of MDF, in several instances MDF-supplemented cortical cultures were grown in the continual presence of antibodies to known growth factors at a range of doses known to inhibit their biological activity in other systems. After $2 \mathrm{~d}$, all cultures were fixed and analyzed for TH immunocytochemistry. Each value represents the mean of duplicate cultures from 2 separate platings.

a Generously provided by Dr. E. M. Johnson, St. Louis, MO.

${ }^{b}$ Purchased from Collaborative Research, Inc.

' Rabbit antimouse EGF. Antibody dilutions used will inhibit binding of $0.625-2.5 \mathrm{mg}$ EGF/well as determined by Ouchterlony Double Immunodiffusion Method.

${ }^{a}$ Purchased from R\&D Systems, Inc.

e Purchased from Sigma Chemical Co.

Guinea pig antimouse NGF. Titer is $\geq 1000$ as determined by Fenton's chick DRG bioassay. 
A. TOTAL RNA

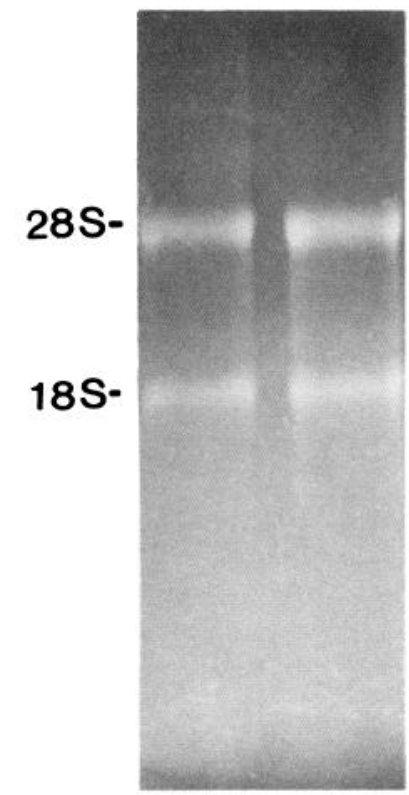

C
B. TH mRNA

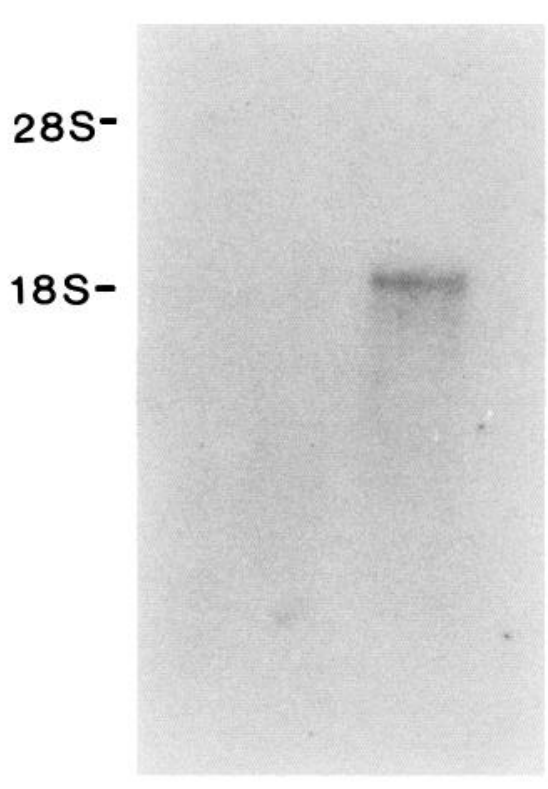

C
C. TH PROTEIN

kD

130-

75-

50-

39-

C S

\section{STANDARD CURVE}
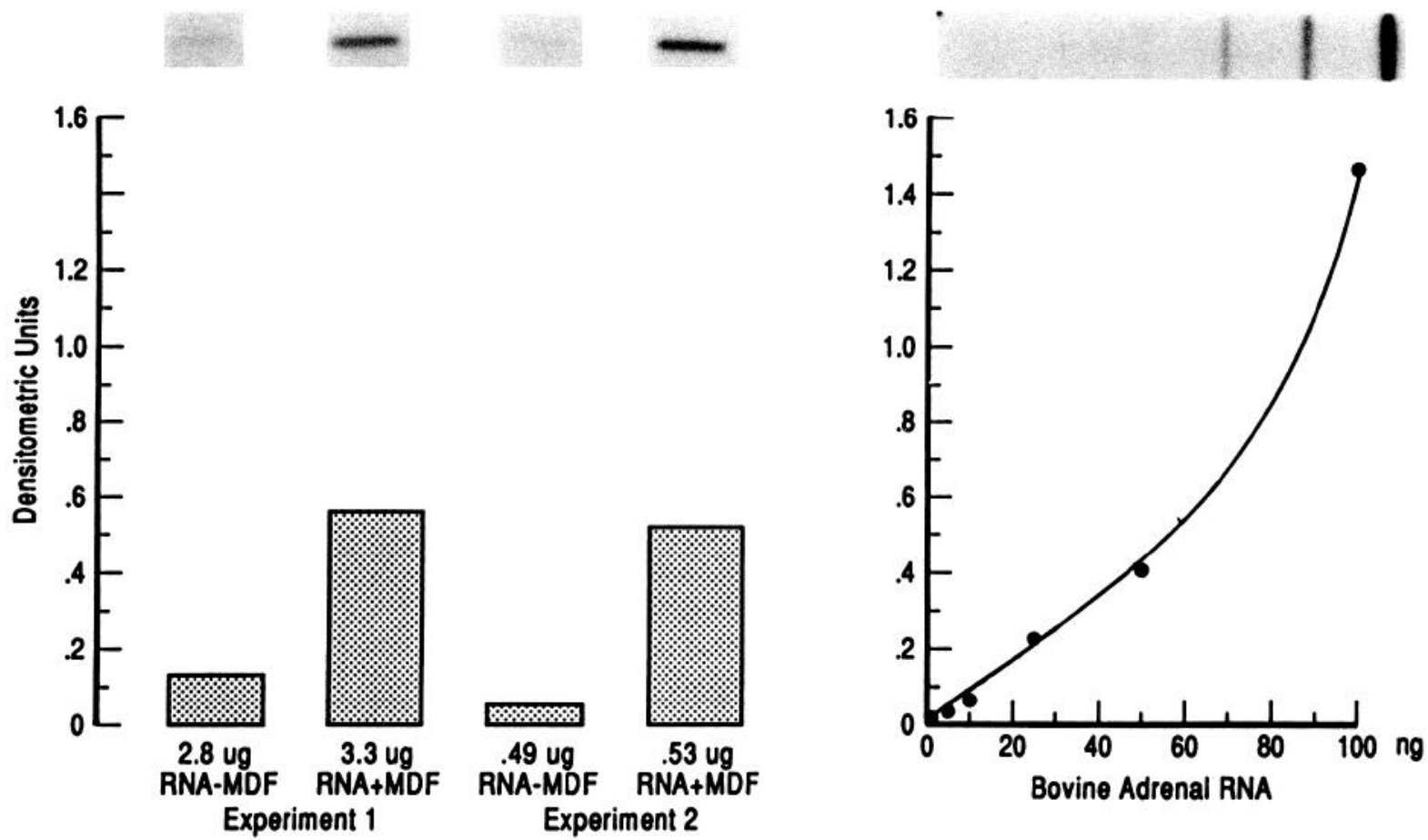

Figure 3. Effect of soluble muscle factor(s) on steady-state levels of TH mRNA in cortical cultures maintained on control ( $C$ ) or muscle fractionsupplemented $(S)$ media. $A$, Total cellular RNA was isolated from cortical cultures grown either alone or in the presence of soluble muscle fraction (12 mg protein $/ \mathrm{ml}$ ). RNA, $20 \mu \mathrm{g}$, was loaded into each lane. $B$, RNA was hybridized with a ${ }^{32} \mathrm{P}$-labeled TH cRNA probe (380 ntd). Following RNase treatment, blots were exposed for $3-5 \mathrm{~d}$ at $-80^{\circ} \mathrm{C}$. $C$, Total RNA $(3.1 \mu \mathrm{g})$ was translated in vitro and immunopreciptated with TH antibodies before fractionation on a $10 \%$ SDS polyacrylamide gel and fluorography. $D$, In 2 separate experiments, equivalent amounts of total RNAs were analyzed in MDF and PBS-treated cortical cultures. Following hybridization with TH cRNA and RNase treatment, the autoradiogram was analyzed 
cerebral cortex grown in the presence of MDF. Twenty-four hours later, the cultures were processed for TH immunocytochemistry.

$\alpha$-Amanitin (Fig. $4 A$ ) reduced the number of neurons expressing $\mathrm{TH}$. While doses below $1 \mu \mathrm{g} / \mathrm{ml}$ had no effect, doses at $10 \mu \mathrm{g} / \mathrm{ml}$ or higher, a range that Roeder (1976) found to be capable of totally inhibiting RNA polymerase II, reduced the number of TH neurons by $70 \%$. The residual number of $\mathrm{TH}$ neurons may contain protein formed prior to the administration of $\alpha$-amanitin. Cycloheximide (Fig. $4 B$ ) also elicited a dosedependent reduction in the numbers of TH neurons. The threshold dose fell between 0.1 and $1.0 \mathrm{ng} / \mathrm{ml}$, with $\mathrm{TH}$ induction completely abolished at maximum doses. The results indicate that both de novo transcription and translation are required for the inductive effects of $\mathrm{MDF}$ on $\mathrm{IH}$.

\section{Effects of other trophic agents on TH expression}

We next examined whether known growth factors, when added to cultures at biologically active doses, could mimic the profound effects of MDF. In no case did incubation with any of the substances listed in Table 6 enhance the expression of TH above the level normally found in control cortical cultures. Moreover, inclusion of antibodies to several known growth factors $\left(\mathrm{NGF}_{\mathrm{ab}}, \mathrm{EGF}_{\mathrm{ab}}, \mathrm{FGF}_{\mathrm{ab}}\right)$ in the media did not reduce the inductive effects of muscle factor(s). These findings suggest that muscle may contain a unique and as yet uncharacterized molecule(s) capable of inducing TH expression.

\section{Discussion}

In the present study we sought to determine the mechanism by which a population of neurons in the embryonic rat cortex that in vivo do not express a CA phenotype will, when grown in culture (Iacovitti et al., 1987) or transplanted into the adult cerebral cortex (Park et al., 1986; Herman et al., 1988), express the CA biosynthetic enzyme TH. By coculturing embryonal cerebral cortex with 3 separate tissues ordinarily present in brain grafts and possibly in cortical cultures, we observed that blood vessels but not glia nor fibroblasts had the capacity to enhance TH expression. Furthermore, it appeared that vascular smooth muscle was the probable source of this "inductive" vascular signal since even greater enhancement in $\mathrm{TH}$ expression was achieved by coculture of the cortical neurons with cells of a smooth muscle line (1440). Other types of muscle, including skeletal, cardiac, and a clonal skeletal muscle line, L6, were also potent inducers of $\mathrm{TH}$ expression in cortex. That the factor(s) in muscle was soluble and diffusible was demonstrated by the fact that muscle-conditioned media was capable of inducing TH in cortical neurons and, more directly, that a soluble extract of muscle cytosol could enhance, in a dose-dependent manner, the number of TH-positive neurons, while muscle membranes had no effect.

Since our previous studies demonstrated that the cortical neurons which are capable of TH expression in culture are postmitotic (Iacovitti et al., 1987), their selective proliferation cannot account for the increase in TH number. Several other mechanisms have therefore been considered. Conceivably, mus-
A. EFFECTS OF $\alpha$-AMANITIN ON MDF-TREATED CORTICAL CULTURES

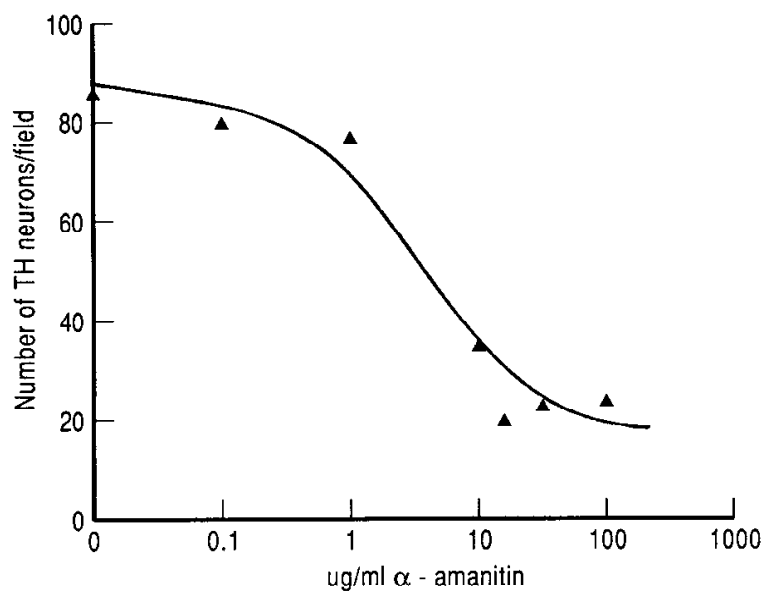

B. EFFECTS OF CYCLOHEXIMIDE ON MDF-TREATED CORTICAL CULTURES

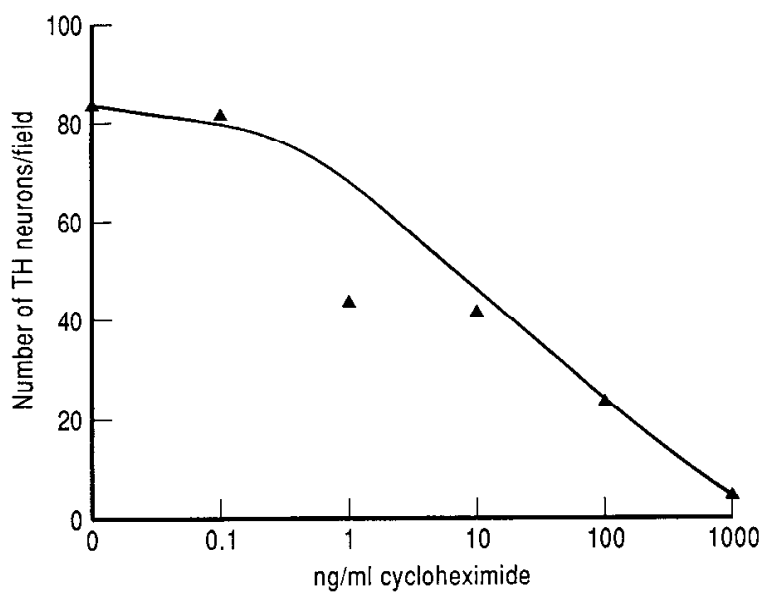

Figure 4. Effect of muscle factor(s) on TH expression in cultured cortex following treatment with varying doses of $\alpha$-amanitin, an RNA polymerase inhibitor $(A)$ or the protein synthesis inhibitor cycloheximide (B). After $24 \mathrm{hr}$ incubation, cultures were fixed and processed for $\mathrm{TH}$ immunocytochemistry and the number of TH neurons were counted in 10 random fields/culture. Values represent the mean of duplicate cultures at each dose tested. All cultures were derived from a single plating.

cle factor(s) could increase the number of neurons expressing $\mathrm{TH}$ in culture (1) by enhancing the survival of all plated neurons or specifically those competent to express $\mathrm{TH}$, or (2) by initiating differentiation of the enzyme in a fixed population of non-CA neurons. Several lines of evidence suggest that the muscle factor(s) promotes neuronal differentiation, not survival. First, in the presence of muscle factor(s), the total number of NSE-positive neurons remains unchanged despite a dramatic rise in the proportion of $\mathrm{TH}$ neurons. Moreover, the same degree of $\mathrm{TH}$ induction is achieved even when muscle extract is added a day after plating when no new neurons are available for recruitment into culture. Finally, the growth of neurons in culture does not appear to be significantly enhanced by supplementation with 
the muscle factor(s). These findings, taken together, suggest that an improvement in the overall survival or health of the neurons in culture is not the underlying mechanism for the enhancement in $\mathrm{TH}$ expression. Rather, it seems most likely that muscle contains a factor(s) that initiates TH expression in an existing population of neurons that do not normally express detectable levels of this enzyme. We, therefore, propose the name musclederived differentiation factor, or MDF, for this putative substance(s).

That the increase in numbers of $\mathrm{TH}$ neurons in cortex is associated with an increase in specific TH mRNA and enzyme activity and requires de novo synthesis of these molecules demonstrates that the phenotypic interconversion is triggered by activation of the TH gene. Whether MDF acts directly on the cortical neuron to produce this activation or requires involvement of the other cell types present in our cultures has not yet been established. Fibroblasts, which themselves do not induce $\mathrm{TH}$ in cortex but which are present in far greater numbers in supplemented cultures, may play an important role in mediating the effects of MDF. The resolution of this question awaits further investigation.

It is not yet clear whether MDF is responsible for the basal level of TH expression seen in control cultures $(0.5 \%$ of plated neurons). Since it is impossible to remove blood vessels from the dissected brain tissue MDF might conceivably be liberated from the vasculature during the dissociation process. Alternatively, it is possible that the $\mathrm{TH}$ neurons present in control cultures represent neurons that express the enzyme in vivo but are not detected by immunocytochemistry. In this regard, it is noteworthy that a small population of perikarya have been observed that transiently express $\mathrm{TH}$ in the postnatal (14-30 d) rat cortex (Berger et al., 1985).

Although skeletal and cardiac muscle cells of the 1440 and L6 cell lines and presumably smooth muscle cells of blood vessels are all capable of $\mathrm{TH}$ induction in cortex, we do not yet know whether this effect is mediated by one molecule common to all muscle types or several different agents. Indeed, muscle has been identified as a reservoir of trophic factors (Giller et al., 1977; Patterson and Chun, 1977; Bennett et al., 1980; Henderson et al., 1981; Weber, 1981; Fukada, 1985; Kaufman et al., 1985; Dohrmann et al., 1986; Steele and Hoffman, 1986; Oppenheim et al., 1988), including neuroleukin (Gurney, 1986), NGF (Levi-Montalcini and Angelletti, 1968), and FGF (Gospodarowicz et al., 1987). None of these, however, effect a change in $\mathrm{TH}$ expression in rat cortex. Moreover, while a number of molecules (Kessler et al., 1986; Saadat and Thoenen, 1986; for review, Varon and Adler, 1981), such as inosine (Zurn and Do, 1988), adenosine (Zurn and Do, 1988), KCl (Walicke et al., 1977), and glucocorticoid (Fukada, 1980; Doupe et al., 1985), can amplify adrenergic properties in adrenergic neurons, they (Table 6) did not mimic the action of MDF and activate expression of an adrenergic enzyme in the nonadrenergic neurons of the cerebral cortex. Hence, MDF may be unique.

If and how this factor(s) functions in vivo remains uncertain. Its presence in blood vessels, however, raises the prospect that such a factor(s) might be present in vivo but may not occur in great enough abundance in cortex to induce expression of the enzyme there, except possibly during early development, in response to neuronal injury or in transplanted tissues where bloodbrain barrier function is deficient (Senjo et al., 1986; Rosenstein, 1987). Since, in preliminary studies, MDF also profoundly enhances TH expression in cultured substantia nigra neurons (Ia- covitti et al., 1988), this substance may also play a critical role in the normal maintenance of CA function in brain-stem CA neurons. Our future studies will explore this possibility.

Irrespective of its identity or its role in vivo, this study has demonstrated that some neurons of the CNS, like those in the periphery have the capacity to change neurotransmitter phenotype in direct response to an agent(s) in their environment. The function of this agent in neuronal differentiation remains to be established.

Note added in proof:

Calcitonin-gene related peptide, which was recently shown to induce $\mathrm{TH}$ and dopamine uptake in the dopaminergic neurons of the olfactory bulb (Denis-Donini, 1989), when added to cortical cultures in concentrations ranging from $10^{-5}$ to $10^{-9}$, does not mimic the effects of MDF.

\section{References}

Ausubel, F. M., R. Brent, R. E. Kingston, D. D. More, J. G. Seidman, J. A. Smith, and K. Struhl, eds. (1987) Current Protocols in Molecular Biology, pp. 4.1.4-4.1.6, Wilcy, Ncw York.

Bennett, M. R., K. Lai, and V. Nurcombe (1980) Identification of embryonic motoneurons in vitro: Their survival is dependent on skeletal muscle. Brain Res. 190: 537-542.

Berger, B., C. Verney, P. Gaspar, and A. Febret (1985) Transient expression of tyrosine hydroxylase immunoreactivity in some neurons of the rat neocortex during postnatal development. Dev. Brain Res. 23: 141-144.

Bottenstein, J. E., and G. H. Sato (1979) Growth of a rat neuroblastoma cell line in serum-free supplemented medium. Proc. Natl. Acad. Sci. USA 76: 514-517.

Bunge, R. P., M. Johnson, and C. D. Ross (1978) Nature and nurture in the development of the autonomic neuron. Science 199: 14091415.

Coyle, J. T. (1972) Tyrosine hydroxylase in rat brain: Cofactor requirements, regional and subcellular distribution. Biochem. Pharmacol. 21: 1935-1944.

Denis-Donini, S. (1989) Expression of dopaminergic phenotypes in the mouth olfactory bulb induced by the calcitonin gene-related peptide. Nature 339: 701-703.

Dohrmann, U., P. Edgar, M. Sendtner, and H. Thoenen (1986) Muscle-derived factors that support survival and promote fiber outgrowth from embryonic chick spinal motor neurons in culture. Dev. Biol. 118: 209-221.

Doupe, A. J., S. C. Landis, and P. H. Patterson (1985) Development of neural crest derivatives: Glucocorticoids, growth factors and chromaffin cell plasticity. J. Neurosci. 5: 2119-2142.

Fukada, K. (1980) Hormonal control of neurotransmitter choice in sympathetic neurone cultures. Nature 287: 553-555.

Fukada, K. (1985) Purification and partial characterization of a cholinergic neuronal differentiation factor. Proc. Natl. Acad. Sci. USA 82: 8795

Giller, E. L., Jr., J. H. Neale, P. N. Bullock, B. K. Schreir, and P. G. Nelson (1977) Choline acetyltransferase activity of spinal cord culture increased by co-culture with muscle and by muscle-conditioned medium. J. Cell. Biol. 74: 16-29.

Gospodarowicz, D., N. Ferrara, L. Schweigerer, and G. Neufeld (1987) Structural characterization and biological functions of fibroblast growth factor. Endocrinol. Rev. 8: 95-114.

Gurney, M. E., S. P. Heinrich, M. R. Lee, and H.-S. Yin (1986) Molecular cloning and expression of neuroleukin, a neurotrophic factor for spinal and sensory neurons. Science 234: 566-573.

Henderson, C. E., M. Huchet, and J.-P. Changeux (1981) Neuritc outgrowth from embryonic chicken spinal neurons is promoted by media conditioned by muscle cells. Proc. Natl. Acad. Sci. USA 78: 2625-2629.

Herman, J. P., N. Abrous, A. Vigny, J. Dulluc, and M. LeMoal (1988) Distorted development of intracerebral grafts: Long-term maintenance of tyrosine hydroxylase-containing neurons in grafts of cortical tissue. Dev. Brain Res. 40: 81-88.

Iacovitti, L., T. H. Joh, D. H. Park, and R. P. Bunge (1981) Dual expression of neurotransmitter synthesis in cultured autonomic neurons. J. Neurosci. 1: 685-690. 
Iacovitti, L., T. H. Joh, V. R. Albert, D. H. Park, D. J. Reis, and G. Teitelman (1985) Partial expression of catecholaminergic traits in cholinergic chick ciliary ganglia: Studies in vivo and in vitro. Dev. Biol. 110: 402-412.

Iacovitti, L., J. Lee, T. H. Joh, and D. J. Reis (1987) Expression of tyrosine hydroxylase in neurons of cultured cerebral cortex: Evidence for phenotypic plasticity in neurons of the CNS. J. Neurosci. 7: 12641270.

Iacovitti, L., M. Evinger, and D. J. Reis (1988) A soluble muscle factor(s) induces tyrosine hydroxylase activity in cultured substantia nigra neurons. Soc. Neurusci. Abstr. 2112: 516.

Kaufman, L. M., S. R. Barry, and J. N. Barrett (1985) Characterization of tissue-derived macromolecules affecting transmitter synthesis in rat spinal cord neurons. Brain Res. 5: 160-166.

Kessler, J. A., G. Conn, and V. B. Hatcher (1986) Isolated plasma membranes regulate neurotransmitter expression and facilitate effects of a soluble brain cholinergic factor. Proc. Natl. Acad. Sci. USA 83: 3528-3532.

Kohler, C., J. B. Everitt, J. Pearson, and M. Goldstein (1983) Immunohistochemical evidence for a new group of catecholamine-containing neurons in the basal forebrain of the monkey. Neurosci. Lett. 37: 161-166.

Levi-Montalcini, R., and P. U. Angelletti (1968) Nerve growth factor. Physiol. Rev. 48: 534-569.

McCarthy, D. K., and J. de Vellis (1980) Preparation of separate astroglial and oligodendroglial cell cultures from rat cerebral tissue. J. Cell Biol. 85: 890-902.

Oppenheim, R. W., L. J. Haverkamp, D. Prevette, J. L. McManaman, and S. H. Appel (1988) Reduction of naturally occurring motoneuron death in vivo by a target-derived neurotrophic factor. Science 240: 919-922.

Park, J. K., T. H. Joh, and F. F. Ebner (1986) Tyrosine hydroxylase is expressed by neocortical neurons after transplantation. Proc. Natl. Acad. Sci. USA 83: 7495-7498.

Patterson, P. H. (1978) Environmental determination of autonomic neurotransmitter functions. Annu. Rev. Neurosci. 1: 1-17.

Patterson, P. H., and L. L. Y. Chun (1977) The induction of acetylcholine synthesis in primary cultures of dissociated rat sympathetic neurons. I. Effects of conditioned medium. Dev. Biol. 56: 263-280.
Roeder, R. G. (1976) Eukaryotic nuclear RNA polymerases. In RNA Polymerase, R. Losick and M. Chamberlin, eds., pp. 285-329, Cold Spring Harbor Laboratory, Cold Spring Harbor, NY.

Rosenstein, J. M. (1987) Neocortical transplants in the mammalian brain lack a blood-brain-barrier to macromolecules. Science 235: 772774.

Saadat, S., and H. Thoenen (1986) Selective induction of tyrosine hydroxylase by cell-cell contact bovine adrenal chromaffin cells is mimicked by plasma membranes. J. Cell Biol. 103: 1991-1997.

Senjo, M., T. Ishibashi, T. Terashima, and Y. Inoue (1986) Correlation between astrogliogenesis and blood-brain-barrier formation: Immunocytochemical demonstration by using astroglia-specific enzyme glutathione-S-transferase. Neurosci. Lett. 66: 39-42.

Specht, L. A., V. M. Pickel, T. H. Joh, and D. J. Reis (1981) Light microscopic immunocytochemical localization of tyrosine hydroxylase in prenatal rat brain. 1. Early ontogeny. J. Comp. Neurol. 199: 233-253.

Steele, J. G., and H. Hoffman (1986) Neurite-promoting activity from fetal skeletal muscle: Partial purification of a high molecular-weight form. J. Neurosci. Res. 15: 323-339.

Sternberger, L. A. (1974) Immunocytochemistry, Prentice-Hall, Englewood Cliffs, NJ.

Teitelman, G., T. H. Joh, L.Grayson, D. H. Park, D. J. Reis, and L. Iacovitti (1985) Cholinergic neurons of the chick ciliary ganglia express adrenergic traits in vivo and in vitro. J. Neurosci. 5: 29-39.

Ungerstedt, U. (1971) Stereotaxic mapping of the monoamine pathways in the rat brain. Acta Physiol. Scand. (Suppl.) 367: 1-48.

Varon, S., and R. Adler (1981) Trophic and specifying factors directed to neuronal cells. Adv. Cell. Neurobiol. 2: 115-163.

Walicke, P. A., R. B. Campenot, and P. H. Patterson (1977) Determination of transmitter function by neuronal activity. Proc. Natl. Acad. Sci. USA 74: 5767-5771.

Weber, M. J. (1981) A diffusable factor responsible for the determination of cholinergic functions in cultured sympathetic neurons. J. Biol. Chem. 256: 3447-3452.

Zurn, A. D., and K. Q. Do (1988) Purine metabolite inosine is an adrenergic neurotrophic substance for cultured chicken sympathetic neuron. Proc. Natl. Acad. Sci. USA 85: 8301-8305. 